\title{
Antidepressant medication treatment patterns in Asian patients with major depressive disorder
}

\author{
This article was published in the following Dove Press journal: \\ Patient Preference and Adherence \\ II March 2015 \\ Number of times this article has been viewed
}

\author{
Diego Novick' \\ William Montgomery ${ }^{2}$ \\ Victoria Moneta ${ }^{3}$ \\ Xiaomei Peng ${ }^{4}$ \\ Roberto Brugnoli ${ }^{5}$ \\ Josep Maria Haro 3 \\ 'Eli Lilly and Company, Windlesham, \\ Surrey, UK; ' ${ }^{2}$ Eli Lilly Australia Pty \\ Ltd, West Ryde, Australia; ${ }^{3}$ Parc \\ Sanitari Sant Joan de Déu, CIBERSAM, \\ Universitat de Barcelona, Barcelona, \\ Spain; ${ }^{4}$ Eli Lilly and Company, \\ Indianapolis, IN, USA; ${ }^{5}$ Department \\ of Neuroscience, School of Medicine, \\ Sapienza University of Rome, Rome, \\ Italy
}

Purpose: To describe pharmacological treatment patterns in Asian patients with major depressive disorder (MDD), including duration of treatment, reasons for medication discontinuation, rate of medication nonadherence, factors associated with medication nonadherence, and impact of medication nonadherence on depression outcomes.

Patients and methods: Data were from a prospective, observational 3-month study of East Asian MDD inpatients from 40 sites in six East Asian countries who initiated antidepressant treatment at baseline $(\mathrm{n}=569)$. Assessments included the Clinical Global Impression-Severity scale (CGI-S), 17-item Hamilton Depression Rating Scale (HAMD-17), painful physical symptoms, response and remission, employment status, quality of life (QoL) (EuroQOL Questionnaire-5 Dimensions [EQ-5D]) and health state using the visual analog scale, adherence by clinician opinion, and patient self-report. Cox proportional hazards modeling, Kaplan-Meier survival analysis, and regression modeling were employed.

Results: Median time to discontinuation for any reason was 70 days (95\% confidence interval: 47 ; 95). Reasons for discontinuation were inadequate response in $64.1 \%$, nonadherence in $6.2 \%$, and adverse events in $4.1 \% ; 25.6 \%$ who discontinued experienced an adequate response to treatment. In those patients who had an adequate response, age and country were significantly associated with time to medication discontinuation. Patient-reported nonadherence was $57.5 \%$ and clinician-reported nonadherence was $14.6 \%$ (62/426). At 3 months, nonadherent patients had significantly higher disease severity (CGI-S, $P=0.0001$; HAMD-17, $P<0.0001$ ), lower QoL ratings (EQ-5D tariff, $P=0.0007$; EQ-5D visual analog scale, $P=0.0024$ ), and lower response and remission rates (both $P<0.0001$ ) compared with adherent patients. The odds of response and remission were greater among adherent patients.

Conclusion: Early discontinuation of antidepressants among Asian MDD patients was high. A total of $25.6 \%$ who discontinued prematurely were experiencing an adequate response to treatment. Nonadherent patients had significantly higher disease severity, lower QoL ratings, and lower response and remission rates compared with adherent patients.

Keywords: adherence, Asian, major depressive disorder, treatment

\section{Introduction}

The psychiatric condition, major depressive disorder (MDD), is associated with psychological, behavioral, and physical symptoms. In many patients, MDD requires long-term antidepressant treatment to prevent relapse, making adherence with therapy a crucial factor in relapse prevention. ${ }^{1}$ Clinical guidelines recommend several months of antidepressant maintenance treatment for MDD; for example, 6 months of treatment are recommended in the National Institute of Clinical Excellence (NICE) depression guidelines. $^{2}$

While clinical guidelines recommend prolonged maintenance treatment, early discontinuation of treatment is usually high and adherence with therapy in the real-world
Correspondence: Diego Novick Lilly Research Centre, Erl Wood Manor, Sunninghill Road, Windelsham, Surrey GU20 6PH, UK

Tel +44 I 276483832

Fax +44 I276483 I92

Email novick_diego@lilly.com 
setting can be poor. Nonadherence with antidepressant therapy in Western countries has been estimated to be $40 \%-70 \%,{ }^{3-6}$ and it has been suggested that nonadherence in Asian countries may be no better. ${ }^{7,8}$ A retrospective chart review of 367 Japanese patients with MDD, for example, revealed that fewer than $50 \%$ of patients continued antidepressant treatment for 6 months. ${ }^{9}$ Other studies also report medication adherence to be poor among Asian patients with MDD, with at least $50 \%$ of patients found to be nonadherent to antidepressant medication. . $^{70,11}$

Understanding the reasons for nonadherence with antidepressant therapy in MDD will help clinicians to manage this problem. Medication discontinuation may occur due to treatment-related factors, such as the completion of a course of maintenance treatment, but it may also occur due to a lack of efficacy, or adverse events when treatment is poorly tolerated. ${ }^{1}$ Medication nonadherence is also associated with a number of patient-related factors including young age, being a student or in paid employment, a poor doctor-patient relationship, low level of income, and a poor understanding of the importance of continuing medication. ${ }^{1,11,12}$

The analysis of antidepressant treatment patterns in MDD increases our understanding of the reasons for nonadherence. Most of the studies of medication adherence in Asia conducted to date, however, have been cross-sectional or based on the analysis of retrospective claims data, so have provided little information that is useful in clinical practice. Among Asian patients, information on the level of nonadherence and impact of nonadherence on patient outcomes is particularly limited.

The overall objective of the present analysis was to describe pharmacological treatment patterns in Asian patients with MDD. Specific objectives included description of the duration of antidepressant treatment, the reasons for medication discontinuation, estimation of the rate of medication nonadherence, exploration of the factors associated with medication nonadherence, and investigation of the impact of medication nonadherence on the outcomes of depression.

\section{Materials and methods \\ Study design and population}

This was a post hoc analysis of data from a prospective, observational study designed to assess the frequency of somatic symptoms in East Asian patients who received treatment for an acute MDD episode. The study was conducted in the psychiatric care setting and enrolled patients from 40 study sites across six East Asian countries and regions (specifically mainland China $[\mathrm{n}=300,33.0 \%]$, Hong Kong [ $\mathrm{n}=89$,
9.8\%], Malaysia [n=95, 10.5\%], Singapore [n=30, 3.3\%], South Korea [n=197, 21.7\%] and Taiwan [n=198, 21.8]). Recruitment occurred from June 14, 2006 to February 15, 2007 , with a follow-up period of 3 months. Previous publications have reported the baseline characteristics of the patients with and without painful physical symptoms (PPS) ${ }^{13}$ and changes in quality of life (QoL), patterns of treatment, and severity of disease over the 3 months of follow-up. ${ }^{14}$

Study entry criteria were as follows: inpatients and outpatients; aged $\geq 18$ years; presenting with a new or first episode of MDD (defined according to the Diagnostic and Statistical Manual of Mental Disorders, Fourth Edition Text Revision [DSM-IV-TR $]^{15}$ or International Classification of Diseases, 10th Revision [ICD-10] ${ }^{16}$ diagnostic criteria); moderately ill or worse (ie, a Clinical Global Impression of Severity scale [CGI-S $]^{17}$ score $\geq 4$ ); no symptoms of depression for $\geq 2$ months prior to the current episode; and consent to participate in the study.

Exclusion criteria were as follows: persistence of the current depressive episode for $\geq 6$ (continuous) months; a previous or current diagnosis of schizophrenia, schizophreniform disorder, schizoaffective disorder, bipolar disorder, or dementia; the presence of chronic, treatment-resistant pain or inflammatory pain related to an identified medical condition; and current participation in another study (with a treatment intervention or an investigational drug).

All patients who satisfied the entry criteria were enrolled up to the required sample size. No further selection or stratification was performed.

No restrictions nor recommendations were made regarding treatments prescribed during the study; all treatment decisions were based solely on the clinician's usual practice when providing care for MDD patients. Reporting of adverse events was conducted in line with each country's rules, regulations, and legislation. The study was performed in accordance with the ethical principles that have their origin in the Declaration of Helsinki and that are consistent with the International Conference on Harmonization good clinical practice guidelines. Institutional or ethical review board approval was obtained from at least one site in each country or region. Prior to study enrollment, written, informed consent was obtained from all patients (or their legal representative).

\section{Measures}

Data collected at the baseline visit included demographic and clinical data. The severity of depression was assessed at baseline and again at 3 months using two measures: the 17-item Hamilton Depression Rating Scale (HAMD-17) ${ }^{18}$ 
and the clinician-rated CGI-S. Consistency of HAMD-17 ratings between clinicians was ensured by training and assessment (rating of a videotaped patient interview). A maximum variation of +3 or -3 from the prespecified HAMD-17 total score was considered acceptable, plus $60 \%$ agreement with the 17 individual items. In case of investigators outside the acceptable range, retraining was performed until adequate consistency with other raters was achieved.

A mean score of greater than or equal to 2 out of a rating of 1 to 5 for the pain-related items of the modified Somatic Symptom Inventory (SSI) (which includes muscular soreness, headache, lower back pain, abdominal pain, and joint, neck, heart, and chest pain) defined the presence of PPS at baseline. ${ }^{19}$ The SSI is a patient self-report scale that measures (on a scale of 1 ["not at all"] to 5 ["a great deal"]) the extent to which 28 somatic symptoms bothered the patient during the previous week.

Response was defined as a reduction of 50\% in HAMD-17 total score from baseline to endpoint. Remission was defined as a HAMD-17 total score of $\leq 7$ at study endpoint.

Patient perception of QoL and health status was assessed using the EuroQOL Questionnaire-5 Dimensions (EQ-5D), ${ }^{20}$ which is a self-rated, generic, health-related QoL instrument that consists of two parts: 1) five questions on general health covering the dimensions of mobility, self-care, usual activities, pain/discomfort, and anxiety/depression (EQ-5D); and 2) a visual analog scale (VAS) that patients use to assess their current level of health on the day of scoring from 0 (worst imaginable health state) to 100 (best imaginable health state) (EQ-5D VAS). The five questions on general health were translated into QoL tariff scores using the available UK population tariffs. $^{21}$

Data describing patterns of treatment (including the specific antidepressants and other medications prescribed) were collected at baseline and during the follow-up period. Antidepressants were classified into the following groups: tricyclic and tetracyclic antidepressants, selective serotonin reuptake inhibitors (SSRIs), serotonin norepinephrine reuptake inhibitors, and other antidepressants (dopamine reuptake inhibitors, monoamine oxidase inhibitors, noradrenergic and specific serotonergic antidepressants).

Adherence was evaluated at 3 months both by the clinician and by the patient. Clinicians were asked to provide their opinion on whether the patient had been adherent with the prescribed medication(s) for MDD since the baseline visit; Patients taking a daily medication dose between $80 \%$ and $120 \%$ of the prescribed medication were considered adherent (as patients may take more medication than prescribed).
Patients were asked how regularly they took the medications prescribed for MDD since the baseline visit, with the options of: 1, "I never missed taking my medicine"; 2 , "I missed only a couple of times but basically took all medicine"; 3, "I missed taking the medicine several times but took at least half of it"; 4, "I took less than half of what was prescribed"; and 5, "I stopped taking the medicine altogether". Only those patients answering 1 were considered adherent.

Medication discontinuation refers to the medication no longer being prescribed by his/her doctor. The date of medication discontinuation was defined as the date that the patient was no longer prescribed the antidepressant medication. If the patient started two or more medications at the baseline visit, the medication discontinuation date was taken as the first date of medication discontinuation. Reasons for medication discontinuation were adequate response, adverse event, inadequate response, and nonadherence.

\section{Statistical analysis}

Patients who initiated an antidepressant medication at baseline and were also evaluated at 3 months were included in this analysis. Descriptive statistics were used to characterize patients at study entry.

Cox proportional hazards modeling was used to evaluate the possible effect of covariables on time to discontinuation. Survival analysis with competing risks were used to analyze the influence of different reasons for discontinuation. A KaplanMeier product limit estimation method was used to assess the time to medication discontinuation. The association between adherence and the outcomes of depression were analyzed using regression models; multiple linear regression was used for continuous variables (HAMD-17 score, CGI-S, EQ-5D score, and VAS), and logistic regression was used for categorical variables (response and remission). All models were adjusted by age, sex, the baseline value of the outcome variable, and any other variable associated with the outcome. In the case of remission and response, HAMD-17 was included as a covariate. The main analysis was conducted using clinician-reported adherence. A sensitivity analysis was conducted using patientreported adherence instead of clinician-reported adherence.

All statistical analyses were performed using $\mathrm{SAS}^{\odot}$ version 9.2 for Windows ${ }^{\mathrm{TM}}$ (SAS Institute Inc., Cary, NC, USA). The level of statistical significance was defined a priori as a two-sided $P$-value of 0.05 .

\section{Results}

A total of 909 patients were enrolled in the study; of these patients, 13 patients were not taking antidepressants, and 247 , 
80, and 569 patients started antidepressant treatment before, after, and at the baseline visit, respectively. The patients included in this analysis were the 569 patients who started antidepressant treatment at the baseline visit.

Comparison of the baseline demographics and clinical characteristics of the patients who were followed (ie, with both baseline and endpoint assessment, $n=430,75.6 \%$ ) and those lost to follow-up (ie, with baseline assessment only, $\mathrm{n}=139,24.4 \%$ ) revealed that there were no significant differences between the groups in the proportion of women, severity of depression (HAMD-17), QoL (EQ-5D tariff and VAS score), or comorbidities (Table 1). There were significant differences between the groups with regard to PPS+ status, employment status, and disease severity; compared with patients who were assessed at 3 months, patients lost to follow-up were more likely to be PPS $+(P=0.0388)$, to be in full-time employment $(P=0.0117)$, and to have less severe disease (CGI-S score) $(P=0.0094)$.

Mean (standard deviation [SD]) age of the 430 patients was 46.25 (SD 14.00) years and 67.4\% were women. Time to medication discontinuation among the 430 patients for whom both baseline and 3-month assessments were available is shown in Figure 1. The rate of medication discontinuation was rapid during the first 10 days, and then slowed thereafter; $242(56.3 \%)$ patients had discontinued their medication by 3 months, and 188 (43.7\%) continued treatment. The median time to discontinuation for any reason was 70 days (95\% confidence interval [CI]: 47; 95). Among the 242 patients who discontinued treatment, the reasons for discontinuation were inadequate response to treatment in 155 (64.1\%) patients, nonadherence in $15(6.2 \%)$ patients, and adverse events in ten $(4.1 \%)$ patients; $62(25.6 \%)$ patients who discontinued experienced an adequate response to treatment. Among the patients experiencing an adequate response to treatment, mean (SD) time to discontinuation was 48.7 (40.1) days, with a median time to discontinuation of 47.5 days. Among the patients experiencing an inadequate response, mean (SD) time to discontinuation was 20.5 (SD 21.1) days, with a median time to discontinuation of 13 days.

Cox regression analysis revealed that, in patients with a good response to treatment, age and country were factors that were significantly associated with time to discontinuation. Older patients discontinued treatment significantly earlier than younger patients (hazard ratio [HR] 1.027 [95\% confidence limits (CL); 1.008; 1.047], $P=0.0049)$. Patients from Hong Kong, Malaysia/Singapore, and Taiwan discontinued treatment significantly later than patients from the People's Republic of China; the HR for time to discontinuation was 0.235 (95\% CL: 0.069; 0.794, $P=0.0198$ ) for Hong Kong, 0.344 (95\% CL: $0.126 ; 0.937, P=0.0370)$ for Malaysia/ Singapore, and 0.356 (95\% CL: $0.153 ; 0.829, P=0.0166$ ) for Taiwan. Other variables (ie, sex, presence of PPS+, and medication) were not significantly associated with discontinuation. In patients with an inadequate response to or intolerant of treatment, country was the only factor that was significantly associated with time to discontinuation; patients

Table I Baseline patient demographics and clinical characteristics $(n=569)$

\begin{tabular}{|c|c|c|c|}
\hline Characteristic & $\begin{array}{l}\text { Patients with only } \\
\text { baseline assessment } \\
(n=139)\end{array}$ & $\begin{array}{l}\text { Patients with baseline } \\
\text { and endpoint assessments } \\
(n=430)\end{array}$ & $P$-value \\
\hline Women, n (\%) & $93(66.9)$ & $290(67.4)$ & 0.9069 \\
\hline Married, n (\%) & $93(66.9)$ & $30 \mathrm{I}(70.0)$ & 0.5962 \\
\hline PPS+, n (\%) & $87(62.6)$ & $226(52.6)$ & 0.0388 \\
\hline \multicolumn{4}{|l|}{ Comorbidities, n (\%) } \\
\hline 0 & $109(79.6)$ & $349(81.5)$ & 0.7575 \\
\hline I & $21(15.3)$ & $63(14.7)$ & \\
\hline $1+$ & $7(5.1)$ & $16(3.7)$ & \\
\hline \multicolumn{4}{|l|}{ Employment status, n (\%) } \\
\hline Full-time & $58(42.6)$ & $140(32.6)$ & 0.0117 \\
\hline Part-time & II (8.I) & $29(6.8)$ & \\
\hline Student & $7(5.1)$ & $27(6.3)$ & \\
\hline Retired & $6(4.4)$ & $65(15.2)$ & \\
\hline Unemployed & $54(39.7)$ & $168(39.2)$ & \\
\hline CGI-S, mean (SD) & $4.60(0.75)$ & $4.76(0.72)$ & 0.0094 \\
\hline HAMD-I7 total score, mean (SD) & $24.24(5.90)$ & $23.96(5.55)$ & 0.6021 \\
\hline EQ-5D tariff score, mean (SD) & $0.48(0.36)$ & $0.44(0.34)$ & 0.1697 \\
\hline EQ-5D VAS score, mean (SD) & $47.50(21.12)$ & $45.80(19.65)$ & 0.3275 \\
\hline
\end{tabular}

Abbreviations: CGI-S, Clinical Global Impression-Severity; EQ-5D, EuroQOL Questionnaire-5 Dimensions; HAMD-17, 17 -item Hamilton Depression Rating Scale; PPS, painful physical symptoms; SD, standard deviation; VAS, visual analog scale. 


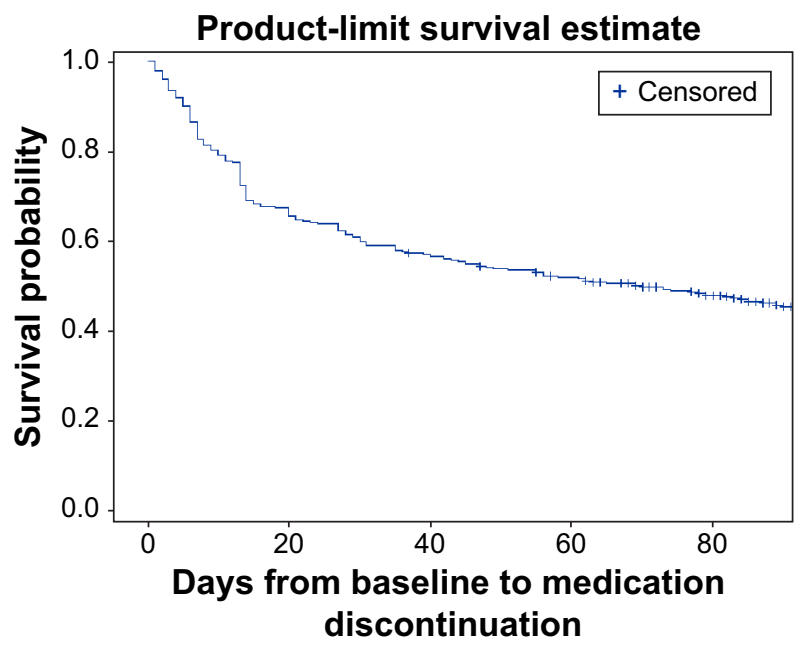

Figure I Time to antidepressant medication discontinuation $(n=430)$.

from Korea discontinued treatment significantly earlier than patients from the People's Republic of China (HR 1.879 [95\% CL: $1.256 ; 2.812], P=0.0022$ ).

Mean daily doses for the antidepressants taken during the study are shown in Table 2. SSRIs were the most commonly prescribed antidepressants.

Information on adherence during the follow-up period was available for 426 patients (in four out of the 430 cases, there was no information about adherence). Patient-reported nonadherence was $57.5 \%$ (245/426), and clinician-reported nonadherence was $14.6 \%(62 / 426)$. Based on clinicianreported adherence data, there were no significant differences in the demographics and clinical characteristics between the two adherence groups at baseline except for a significant difference in EQ-5D tariff scores. Mean (SD) EQ-5D tariff scores were 0.37 (SD 0.36) for nonadherent patients and 0.46 (SD 0.34) for adherent patients $(P=0.0364)$, indicating that QoL at baseline was slightly better in the adherent patients.

Table 2 Mean daily doses taken by study participants for the most commonly used ADs

\begin{tabular}{|c|c|c|c|c|}
\hline \multirow[t]{2}{*}{ Group } & \multirow[t]{2}{*}{ Name } & \multirow{2}{*}{$\begin{array}{l}\text { Number } \\
\text { of patients }\end{array}$} & \multicolumn{2}{|c|}{ Dose (mg/day) } \\
\hline & & & Mean (SD) & Range \\
\hline \multirow[t]{3}{*}{ SSRIs } & Escitalopram & 52 & $9.81(4.20)$ & $5-20$ \\
\hline & Fluoxetine & 60 & $20.50(\mathrm{II} . \mathrm{II})$ & $10-80$ \\
\hline & Paroxetine & 67 & $19.01(6.68)$ & $10-45$ \\
\hline \multirow[t]{2}{*}{ SNRIs } & Venlafaxine & 55 & $89.13(49.46)$ & $25-263$ \\
\hline & Duloxetine & 15 & $38.00(\mid 7.8 I)$ & $30-90$ \\
\hline \multirow[t]{2}{*}{ TCAs } & Dosulepin & 7 & $42.86(18.90)$ & $25-75$ \\
\hline & Trazodone & 5 & $80.00(67.08)$ & $50-200$ \\
\hline \multirow[t]{2}{*}{ Other ADs } & Mirtazapine & 46 & $25.36(11.70)$ & $4-60$ \\
\hline & Bupropion & 12 & I 56.25 (59.47) & $75-300$ \\
\hline
\end{tabular}

Abbreviations: ADs, antidepressants; SD, standard deviation; SNRIs, serotonin norepinephrine reuptake inhibitors; SSRIs, selective serotonin reuptake inhibitors; TCAs, tricyclic and tetracyclic antidepressants.
The remaining demographic and clinical characteristics of the two groups were similar; mean (SD) age was 45.0 (SD 14.8) and 46.3 (SD 13.8) years; $69.4 \%$ and $67.9 \%$ of patients were women; $66.1 \%$ and $70.6 \%$ were married; and $37.1 \%$ and $32.2 \%$ were in full-time employment in nonadherent and adherent patients, respectively. With regard to clinical characteristics, $75.8 \%$ and $82.9 \%$ of patients had no comorbidities; $33.3 \%$ and $39.8 \%$ had experienced a previous MDD episode; $59.7 \%$ and $51.1 \%$ were PPS+; $48.4 \%$ and $59.1 \%$ of patients received SSRIs (the most common antidepressant); and $6.5 \%$ and $8 \%$ received more than one antidepressant, in nonadherent and adherent patients, respectively. Mean (SD) CGI-S scores were 4.69 (SD 0.69) and 4.77 (SD 0.72); HAMD-17 scores were 23.19 (SD 6.36) and 24.07 (SD 5.43); and EQ-VAS scores were 48.84 (SD 20.10) and 45.36 (SD 19.62), in nonadherent and adherent patients, respectively.

Adherence had a significant effect on outcomes at 3 months. Compared with adherent patients, nonadherent patients had significantly higher disease severity (CGI-S, $P=0.0001$; HAMD-17, $P<0.0001)$, significantly poorer QoL (EQ-5D tariff, $P=0.0007$; EQ-5D VAS, $P=0.0024$ ), and significantly lower response $(P<0.0001)$ and remission rates $(P<0.0001)$ (Table 3$)$.

When adjusted for the presence of other clinical and sociodemographic factors using linear regression models, the impact of clinician-reported adherence on outcomes at 3 months was as follows. With regard to depression severity, nonadherent patients had an estimated CGI-S total score that was 0.64 points ( $95 \%$ CI: $0.38 ; 0.90)$ higher, and an estimated HAMD-17 score that was 4.54 points (95\% CI: $3.12 ; 5.96)$ higher than that of adherent patients, indicating that disease severity was lower among adherent patients. With regard to QoL, nonadherent patients had an estimated EQ-5D VAS score that was 7.85 points $(95 \%$ CI: $-12.77 ;-2.94)$ lower, and an estimated EQ-5D tariff score that was 0.13 points (95\% CI: $-0.19 ;-0.06)$ lower than that of adherent patients, indicating that QoL was higher among adherent patients. Response and remission rates also differed significantly with adherence; response rates were $50.8 \%$ in nonadherent patients and $78.6 \%$ in adherent patients $(P<0.0001)$, and remission rates were $31.1 \%$ in nonadherent patients and $60.2 \%$ in adherent patients $(P<0.0001)$. Compared with nonadherent patients (using logistic regression modeling), the odds ratio of response among adherent patients was 3.97 ( $95 \%$ CI: $2.12 ; 7.45$ ), and the odds ratio of remission was 4.30 (95\% CI: $2.21 ; 8.38)$, indicating that the odds of response and remission were greater among adherent patients. 
Table 3 Outcomes at 3 months by clinician-reported adherence $(n=426)$

\begin{tabular}{|c|c|c|c|c|}
\hline Outcome & $\begin{array}{l}\text { Nonadherent } \\
(n=62)\end{array}$ & $\begin{array}{l}\text { Adherent } \\
(\mathrm{n}=364)\end{array}$ & $P$-value & $\begin{array}{l}\text { Adjusted difference } \\
(95 \% \mathrm{Cl})^{\mathrm{a}}\end{array}$ \\
\hline CGI-S, mean (SD) & $2.85(\mathrm{I} .28)$ & $2.19(1.10)$ & 0.0001 & $0.64(0.38 ; 0.90)$ \\
\hline HAMD-I7 total score, mean (SD) & II.59 (7.3I) & $6.98(5.70)$ & $<0.0001$ & $4.54(3.12 ; 5.96)$ \\
\hline EQ-5D tariff score, mean (SD) & $0.68(0.32)$ & $0.82(0.24)$ & 0.0007 & $-0.13(-0.19 ;-0.06)$ \\
\hline EQ-5D VAS score, mean (SD) & $67.20(19.93)$ & 74.68 (19.77) & 0.0024 & $-7.85(-12.77 ;-2.94)$ \\
\hline \multicolumn{5}{|l|}{ Response, n (\%) } \\
\hline No & $30(49.2)$ & $78(21.4)$ & & \\
\hline Yes & $31(50.8)$ & $286(78.6)$ & $<0.0001$ & $3.97(2.12 ; 7.45)$ \\
\hline \multicolumn{5}{|l|}{ Remission, n (\%) } \\
\hline No & $42(68.9)$ & $145(39.8)$ & & \\
\hline Yes & $19(31.1)$ & $219(60.2)$ & $<0.0001$ & $4.30(2.21 ; 8.38)$ \\
\hline
\end{tabular}

Notes: Percentages may not equal 100 due to rounding. ${ }^{2}$ Adjusted difference using linear regression models for CGI-S, HAMD- I7, EQ-5D VAS, and EQ-5D tariff and logistic regression models for response and remission. For linear regression models, values correspond to coefficient ( $95 \% \mathrm{Cl})$; for logistic regression models, values correspond to odds ratio $(95 \% \mathrm{Cl})$.

Abbreviations: 95\% Cl, 95\% confidence interval; CGI-S, Clinical Global Impression-Severity; EQ-5D, EuroQOL Questionnaire-5 Dimensions; HAMD-I7, I7-item Hamilton Depression Rating Scale; SD, standard deviation; VAS, visual analog scale.

In the sensitivity analysis of the impact of adherence on outcomes at 3 months, findings using patient-reported adherence on the severity of depression, QoL, and rates of response and remission were consistent with the findings from clinician-reported adherence, although the size of the differences was smaller.

\section{Discussion}

The discontinuation rate among patients starting antidepressant treatment in our study of Asian MDD patients was high (56.3\%), indicating that more than half of the patients stopped taking their antidepressants before 3 months. This finding of premature discontinuation of antidepressant therapy is in line with estimates of discontinuation of $46 \%-83 \%$ from a wide variety of other studies in Asian patient populations. A general antidepressant discontinuation rate of $50 \%$, for example, was reported for Taiwanese patients, ${ }^{11}$ while discontinuation rates include $46 \%$ at 3 months for Japanese patients, ${ }^{9} 59 \%$ at 6 months among Thai patients, ${ }^{7} 72 \%$ at 6 months among Korean patients, ${ }^{22}$ and $83 \%$ at 6 months among Taiwanese patients. ${ }^{8}$ Studies conducted in Westernized populations include premature antidepressant discontinuation rates of $22 \%-42 \%{ }^{4,5,23,24}$ It is possible, therefore, that discontinuation rates may be higher in Asian populations. These differences could be due to differences in cultural beliefs about medication, mental illness, and stigma surrounding mental disorders. $^{25}$

One-quarter of patients (25.6\%) who discontinued in the present study, were, surprisingly experiencing an adequate response to treatment. This finding highlights the fact that treatment for many Asian MDD patients is not in line with clinical guidelines that recommend that MDD treatment should be maintained for up to 9 months. ${ }^{2,26}$ The present analysis was not designed to explore reasons for early discontinuation, but other studies have suggested that these might include patient perceptions about their treatment (eg, feeling uninvolved in treatment decisions or disagreeing with the diagnosis of MDD), as well as lack of awareness of the need to continue therapy and when they should expect to feel better, ${ }^{5,27,28}$ which might explain stopping therapy while experiencing an adequate response. In a study of Taiwanese MDD patients, lack of insight into MDD was found to predict premature treatment discontinuation, and "self-reported recovery" was the most common reason for discontinuation despite the fact that more than half of these patients had not reached full remission. ${ }^{29}$ Thus, early discontinuation could be due to treatment decisions based on personal criteria from the patient and the physician rather than evidence-based criteria.

Among patients with a good response to treatment, age and country were significantly associated with time to discontinuation, indicating that, compared with younger patients, older patients take their medication for a shorter period of time when it is effective, and that patients in specific countries take their medication for longer. The finding that older age is associated with medication discontinuation in the present analysis differs from other studies that have reported that older age is associated with lower discontinuation rates, ${ }^{5,8,12,29}$ or that this is not a significant factor. ${ }^{1,23}$ Again, these could be due to differences in cultural beliefs from diverse age cohorts in participating countries. The present study did not find sex to be associated with discontinuation, in line with a number of studies, ${ }^{1,23}$ but also did not find medication to be associated with discontinuation, which differs from findings from Hansen et al. ${ }^{23}$ 
The most common reason for discontinuation was inadequate response to treatment (in $64.1 \%$ patients), which is much higher than the $2 \%-22 \%$ of patients who discontinued due to lack of efficacy in other studies..$^{24,30-32}$ Adverse events were the reason for discontinuation in $4.1 \%$ of patients, which is much lower than the discontinuation rate due to adverse events $(8 \%-36 \%)$ reported in some studies, ${ }^{5,24,27,28,32,33}$ but similar to the $5 \%$ of patients who discontinued due to adverse events in others. ${ }^{30,31}$ The median time to discontinuation for any reason was 70 days ( $95 \% \mathrm{CI}: 47 ; 95)$. The finding that the rate of medication discontinuation was rapid initially and then slowed thereafter is in line with other studies that have also reported the antidepressant discontinuation rate to be greatest during the first few weeks of therapy, ${ }^{22,30,32}$ and may imply that interventions trying to increase adherence need to occur early during treatment.

In the present analysis, adherence had a significant impact on outcomes at 3 months. Compared with adherent patients, nonadherent patients had significantly higher disease severity (CGI-S and HAMD-17), lower QoL ratings (EQ-5D tariff and VAS), and lower response and remission rates. These findings were consistent whether adherence was assessed by the clinician or by the patient. This is in line with findings from other studies..$^{34,35}$

\section{Limitations}

A number of limitations should be taken into account when considering the findings of this analysis. Given the observational design of the study, our findings should be interpreted conservatively. Patients were recruited from specialized mental health services and it is unclear whether our results apply to patients in other care settings, such as primary care. A follow-up of 3 months is a short time period for an analysis of medication discontinuation. A substantial number of patients were taking antidepressant medication at the baseline visit, so were not included in the analysis. Due to the observational nature of the study, we were not able to study the effects of early treatment discontinuation. Almost one-fourth of the patients were lost to follow-up; these patients had more PPS and overall disease severity. Adherence was assessed by the clinicians based on limited information, and the use of more precise assessment methods could provide more accurate data on adherence. Finally, adherence and clinical outcomes were assessed by clinicians at the same follow-up visit.

\section{Conclusion}

Premature discontinuation of antidepressants among Asian MDD patients was high; more than half of the patients stopped taking antidepressants before 3 months. Moreover, one-quarter of patients $(25.6 \%)$ with premature discontinuation were experiencing an adequate response to treatment. This finding highlights the fact that treatment for many Asian MDD patients is not in line with clinical guidelines that recommend that MDD treatment should be maintained for up to 9 months. Medication nonadherence had a significant impact on outcomes; nonadherent patients had significantly higher disease severity, lower QoL ratings, and lower response and remission rates at 3 months compared with adherent patients.

\section{Acknowledgments}

This study was funded by Eli Lilly and Company. Sarah Smith, $\mathrm{PhD}$ provided editorial assistance.

\section{Disclosure}

Josep Maria Haro has acted as consultant or speaker for Astra-Zeneca, Eli Lilly, Lundbeck, and Roche. Victoria Moneta conducted the statistical analysis under a contract of Fundació Sant Joan de Déu with Eli Lilly and Company. Diego Novick, William Montgomery, and Xiaomei Peng are employees of Eli Lilly and Company. Roberto Brugnoli has acted as a consultant, received grants, or acted as a speaker in activities sponsored by the following companies: BMS, Eli Lilly, Innovapharma, and Sigma-Tau. The authors report no other conflicts of interest in this work.

\section{References}

1. Rivero-Santana A, Perestelo-Perez L, Pérez-Ramos J, Serrano-Aguilar P, De Las Cuevas C. Sociodemographic and clinical predictors of compliance with antidepressants for depressive disorders: systematic review of observational studies. Patient Prefer Adherence. 2013;7: 151-169.

2. National Institute for Health and Clinical Excellence (NICE). Depression in Adults: The Treatment and Management of Depression in Adults. NICE Clinical Guidance 90. London: NICE; 2009. Available from: http://www. nice.org.uk/guidance/cg90/resources/guidance-depression-in-adults-pdf. Accessed January 23, 2014.

3. Brown C, Battista DR, Bruehlman R, Sereika SS, Thase ME, DunbarJacob J. Beliefs about antidepressant medications in primary care patients: relationship to self-reported adherence. Med Care. 2005;43: 1203-1207.

4. Olfson M, Marcus SC, Tedeschi M, Wan GJ. Continuity of antidepressant treatment for adults with depression in the United States. Am J Psychiatry. 2006;163:101-108.

5. Woolley SB, Fredman L, Goethe JW, Lincoln AK, Heeren T. Hospital patients' perceptions during treatment and early discontinuation of serotonin selective reuptake inhibitor antidepressants. J Clin Psychopharmacol. 2010;30:716-719.

6. Peveler R, George C, Kinmonth AL, Campbell M, Thompson C. Effect of antidepressant drug counselling and information leaflets on adherence to drug treatment in primary care: randomised controlled trial. BMJ. 1999; 319(7210):612-615.

7. Prukkanone B, Vos T, Burgess P, Chaiyakunapruk N, Bertram M. Adherence to antidepressant therapy for major depressive patients in a psychiatric hospital in Thailand. BMC Psychiatry. 2010;10:64. 
8. Wu CS, Shau WY, Chan HY, Lai MS. Persistence of antidepressant treatment for depressive disorder in Taiwan. Gen Hosp Psychiatry. 2013;35: 279-285.

9. Sawada N, Uchida H, Suzuki T, et al. Persistence and compliance to antidepressant treatment in patients with depression: a chart review. BMC Psychiatry. 2009;9:38.

10. Lee MS, Lee HY, Kang SG, et al. Variables influencing antidepressant medication adherence for treating outpatients with depressive disorders. J Affect Disord. 2010;123:216-221.

11. Yeh MY, Sung SC, Yorker BC, Sun CC, Kuo YL. Predictors of adherence to an antidepressant medication regimen among patients diagnosed with depression in Taiwan. Issues Ment Health Nurs. 2008;29: 701-717.

12. Shigemura J, Ogawa T, Yoshino A, Sato Y, Nomura S. Predictors of antidepressant adherence: results of a Japanese Internet-based survey. Psychiatry Clin Neurosci. 2010;64:179-186.

13. Lee MS, Yum SY, Hong JP, et al. Association between painful physical symptoms and clinical outcomes in Korean patients with major depressive disorder: a three-month observational study. Psychiatry Investig. 2009;6:255-263.

14. Ang QQ, Wing YK, He Y, et al. Association between painful physical symptoms and clinical outcomes in East Asian patients with major depressive disorder: a 3-month prospective observational study. Int J Clin Pract. 2009;63:1041-1049.

15. American Psychiatric Association (APA). Diagnostic and Statistical Manual of Mental Disorders, Fourth Edition Text Revision (DSMIV-TR). Washington, DC: American Psychiatric Association; 2000.

16. World Health Organization (WHO). International Classification of Diseases and Related World Health Problems. Geneva: WHO; 2007.

17. Guy W. ECDEU Assessment Manual for Psychopharmacology, Revised. Bethesda, MD: US Department of Health, Education, and Welfare; 1976.

18. Hamilton M. A rating scale for depression. J Neurol Neurosurg Psychiatry. 1960;23:56-62.

19. Kroenke K, Spitzer RL, Williams JB, et al. Physical symptoms in primary care. Predictors of psychiatric disorders and functional impairment. Arch Fam Med. 1994;3:774-779.

20. Brooks R, Rabin R, de Charro F, editors. The Measurement and Valuation of Health Status using EQ-5D: A European Perspective. Dordrecht: Kluwer Academic Publishers; 2003.

21. Kind P, Hardman G, Macran S. UK Population Norms for EQ-5D [working paper \#172]. York: York Centre for Health Economics; 1999.

22. Lee YM, Lee KU. Time to discontinuation among the three secondgeneration antidepressants in a naturalistic outpatient setting of depression. Psychiatry Clin Neurosci. 2011;65:630-637.
23. Hansen DG, Vach W, Rosholm JU, Søndergaard J, Gram LF, Kragstrup J. Early discontinuation of antidepressants in general practice: association with patient and prescriber characteristics. Fam Pract. 2004;21:623-629.

24. Wise TN, Wiltse CG, Iosifescu DV, Sheridan M, Xu JY, Raskin J. The safety and tolerability of duloxetine in depressed elderly patients with and without medical comorbidity. Int J Clin Pract. 2007;61:1283-1293.

25. Fancher TL, Lee D, Cheng JKY, Yang MS, Yang L. Interventions to improve adherence to psychotropic medication in clients of Asian descent: a systematic review. Asian Am J Psychol. 2014;5:22-34.

26. American Psychiatric Association (APA). Practice Guideline for the Treatment of Patients With Major Depressive Disorder. 3rd ed. Arlington, VA: American Psychiatric Press; 2010. Available from: http://psychiatryonline.org/pb/assets/raw/sitewide/practice_guidelines/ guidelines/mdd.pdf. Accessed January 23, 2014.

27. Bull SA, Hunkeler EM, Lee JY, et al. Discontinuing or switching selective serotonin-reuptake inhibitors. Ann Pharmacother. 2002;36:578-584.

28. Bull SA, Hu XH, Hunkeler EM, et al. Discontinuation of use and switching of antidepressants: influence of patient-physician communication. JAMA. 2002;288:1403-1409.

29. Hung CI, Wang SJ, Liu CY, Hsu SC, Yang CH. Comorbidities and factors related to discontinuation of pharmacotherapy among outpatients with major depressive disorder. Compr Psychiatry. 2011;52:370-377.

30. Weissman J, Flint A, Meyers B, et al; STOP-PD Study Group. Factors associated with non-completion in a double-blind randomized controlled trial of olanzapine plus sertraline versus olanzapine plus placebo for psychotic depression. Psychiatry Res. 2012;197:221-226.

31. Plesnicar BK. Efficacy and tolerability of venlafaxine extended release in patients with major depressive disorder. Psychiatr Danub. 2010;22:413-417.

32. Hudson JI, Perahia DG, Gilaberte I, Wang F, Watkin JG, Detke MJ. Duloxetine in the treatment of major depressive disorder: an open-label study. BMC Psychiatry. 2007;7:43.

33. Gaynor PJ, Gopal M, Zheng W, Martinez JM, Robinson MJ, Marangell LB. A randomized placebo-controlled trial of duloxetine in patients with major depressive disorder and associated painful physical symptoms. Curr Med Res Opin. 2011;27:1849-1858.

34. Aikens JE, Nease DE Jr, Nau DP, Klinkman MS, Schwenk TL. Adherence to maintenance-phase antidepressant medication as a function of patient beliefs about medication. Ann Fam Med. 2005;3:23-30.

35. Melfi CA, Chawla AJ, Croghan TW, Hanna MP, Kennedy S, Sredl K. The effects of adherence to antidepressant treatment guidelines on relapse and recurrence of depression. Arch Gen Psychiatry. 1998;55: $1128-1132$.
Patient Preference and Adherence

\section{Publish your work in this journal}

Patient Preference and Adherence is an international, peer-reviewed, open access journal that focuses on the growing importance of patient preference and adherence throughout the therapeutic continuum. Patient satisfaction, acceptability, quality of life, compliance, persistence and their role in developing new therapeutic modalities and compounds to optimize

\section{Dovepress}

clinical outcomes for existing disease states are major areas of interest for the journal. This journal has been accepted for indexing on PubMed Central. The manuscript management system is completely online and includes a very quick and fair peer-review system, which is all easy to use. Visit http://www. dovepress.com/testimonials.php to read real quotes from published authors. 